\title{
Fifteen-year follow-up of relapsed indolent non-Hodgkin lymphoma patients vaccinated with tumor-loaded dendritic cells
}

\author{
Giovanni Fucà (D , ${ }^{1}$ Margherita Ambrosini, ${ }^{1}$ Luca Agnelli, ${ }^{2}$ Silvia Brich, ${ }^{2}$ \\ Francesco Sgambelluri, ${ }^{3}$ Roberta Mortarini, ${ }^{3}$ Serenella M Pupa, ${ }^{4}$ Michele Magni, ${ }^{1}$ \\ Liliana Devizzi, ${ }^{5}$ Paola Matteucci, ${ }^{5}$ Antonello Cabras, ${ }^{2}$ Roberta Zappasodi, ${ }^{6}$ \\ Francesca De Santis, ${ }^{1}$ Andrea Anichini, ${ }^{3}$ Filippo De Braud, ${ }^{1,7}$ Alessandro M Gianni, ${ }^{8}$ \\ Massimo Di Nicola ${ }^{1}$
}

To cite: Fucà G, Ambrosini M, Agnelli L, et al. Fifteen-year follow-up of relapsed indolent non-Hodgkin lymphoma patients vaccinated with tumor-loaded dendritic cells. Journal for ImmunoTherapy of Cancer 2021;9:e002240. doi:10.1136/ jitc-2020-002240

- Additional supplemental material is published online only. To view, please visit the journal online (http://dx.doi.org/10. 1136/jitc-2020-002240).

Accepted 08 May 2021

\section{Check for updates}

(c) Author(s) (or their employer(s)) 2021. Re-use permitted under CC BY-NC. No commercial re-use. See rights and permissions. Published by BMJ.

For numbered affiliations see end of article.

\section{Correspondence to} Dr Massimo Di Nicola; massimo.dinicola@ istitutotumori.mi.it

\section{ABSTRACT}

We previously published the results of a pilot study showing that vaccination with tumor-loaded dendritic cells (DCs) induced both $\mathrm{T}$ and $\mathrm{B}$ cell response and produced clinical benefit in the absence of toxicity in patients with relapsed, indolent non-Hodgkin lymphoma (iNHL). The purpose of the present short report is to provide a 15-year follow-up of our study and to expand the biomarker analysis previously performed. The long-term follow-up highlighted the absence of particular or delayed toxicity and the benefit of active immunization with DCs loaded with autologous, heatshocked and UV-C treated tumor cells in relapsed iNHL (5-year and 10-year progression-free survival (PFS) rates: $55.6 \%$ and $33.3 \%$, respectively; 10 -year overall survival (OS) rate: $83.3 \%$ ). Female patients experienced a better PFS $(p=0.016)$ and a trend towards a better OS $(p=0.185)$ compared with male patients. Of note, we observed a non-negligible fraction of patients (22\%) who experienced a long-lasting complete response. In a targeted gene expression profiling of pre-treatment tumor biopsies in 11 patients with available formalin-fixed, paraffin-embedded tissue, we observed that KIT, ATG12, TNFRSF10C, PBK, ITGA2, GATA3, CLU, NCAM1, SYT17 and LTK were differentially expressed in patients with responder versus non-responder tumors. The characterization of peripheral monocytic cells in a subgroup of 14 patients with available baseline blood samples showed a higher frequency of the subset of $\mathrm{CD} 14^{++} \mathrm{CD} 16^{+}$cells (intermediate monocytes) in patients with responding tumors. Since in patients with relapsed iNHL the available therapeutic options are often incapable of inducing a long-lasting complete remission and can be sometimes characterized by intolerable toxicity, we think that the encouraging results of our long-term follow-up analysis represent a stimulus to further investigate the role of active vaccination in this specific setting and in earlier lines of therapy and to explore novel combinatorial strategies encompassing other innovative immunotherapy agents, such as immune-checkpoint inhibitors.

\section{BACKGROUND}

Indolent non-Hodgkin lymphoma (iNHL) is a class of lymphoid neoplasms including various subtypes (eg, follicular lymphoma and lymphoplasmacytic lymphoma) and characterized by a good response to frontline treatment, even if quite difficult to cure. ${ }^{1}$ Indeed, relapse is usually common after several years, and in patients with relapsed iNHL, antiCD20 monoclonal antibodies, alone or in combination with lenalidomide or chemotherapy, PI3K inhibitors and BTK inhibitors are valuable options, but none of them are curative and toxicity is a concern, especially in heavily pretreated patients. ${ }^{2-7}$

We previously reported that vaccination with tumor-loaded dendritic cells (DCs) was able to induce both $\mathrm{T}$ and $\mathrm{B}$ cell response and produced clinical benefit in absence of toxicity in patients with relapsed iNHL. ${ }^{89}$ Of note, our DC-loading strategy encompassed the use of apoptotic and necrotic cell bodies derived from autologous tumors to exploit the immunoadjuvant effect of immunogenic tumor cell death. ${ }^{10}$

We already investigated the biomarkers associated with the clinical outcomes and response dynamics of our vaccination strategy, observing that a post-vaccination reduction in the frequency of circulating regulatory $\mathrm{T}$ cells was associated with tumor response, as well as an increase in the frequency of circulating natural killer(NK) cells with a cytotoxic immunophenotype. ${ }^{8}$ Furthermore, we already demonstrated that our vaccination strategy promoted a tumor-specific B cell immune response ${ }^{89}$ and that the extent of calreticulin and HSP90 expression (markers of immunogenic cell death) in the vaccine antigenic cargo was associated with tumor response. ${ }^{10}$ The purpose of the present short report is to provide a 15 -year follow-up update 
of our previously published pilot study and to expand the biomarker analysis previously performed.

\section{METHODS \\ Patients' population}

The main inclusion criteria of our pilot study were: diagnosis of iNHL relapsing after at least one chemoradiotherapy regimen, presence of measurable disease, age of 18 years or older and no more than six prior treatment regimens. iNHL was defined as lymphoplasmocytoid (LP) or follicular (FL) grades 1-3A B cell lymphoma as per the REAL classification. ${ }^{11}$ All patients gave written informed consent before enrollment, and the study was conducted in accordance with the Declaration of Helsinki.

\section{Study treatment}

Study treatment consisted in four doses of autologous DCs loaded with autologous, heat-shocked and UV-C treated tumor cells administered subcutaneously in close vicinity to axillary and inguinal lymphnodes at a 2-week interval. Vaccine preparation has been extensively reported in the previous publication. ${ }^{8}$ Briefly, tumor cells were isolated from lymphnodes by mechanical dissociation for 16 patients and from peripheral blood by leukapheresis for two patients. Tumor cells were purified by a high-gradient immunomagnetic technique and subsequently heatshocked, with the aim of increasing the immunogenic activity. Finally, apoptosis was induced in tumor cells by irradiation (100 Gy) and UV-C treatment. Immature DCs were obtained by culturing peripheral blood cells for 5 days with recombinant human granulocyte-macrophage colony-stimulating factor and interleukin 4 , then cocultured for 48 hours with the heat-shocked, irradiated and UV-C-treated tumor cells at a 1:2 ratio. Tumor necrosis factor-alpha was added for the last 12 hours of culture to promote DCs further maturation. Tumor-loaded DCs were suspended in $1 \mathrm{~mL}$ of $0.9 \% \mathrm{NaCl}$ to be injected subcutaneously. Disease response was assessed using the Cheson criteria. ${ }^{12}$ Responding tumors were defined as tumors showing an objective response.

\section{Statistical analyses}

Progression-free survival (PFS) was defined as the time from the last vaccine dose administration until disease progression or death, whichever occurred first. Overall survival (OS) was defined as the time from the last vaccine dose administration until death. Low disease burden was defined as the presence of nodal masses $\leq 3 \mathrm{~cm}$ and no massive bone marrow involvement, whereas high disease burden was defined as the presence of nodal masses $>3 \mathrm{~cm}$ and/or massive bone marrow involvement. Survival analysis was performed using the Kaplan-Meier estimator. Survival curves were compared by means of the log-rank test. In order to identify in a univocal and anonymized way the enrolled patients, unique progressive numbers (UPNs) were used consistently with the previous report. ${ }^{8}$ The data cut-off date for the present analysis was December 1, 2019.

\section{Immune-targeted gene expression profiling}

Total RNA was extracted from formalin-fixed and paraffinembedded (FFPE) tumor tissue using the RNA isolation kit (Roche, Mannheim, Germany), according to manufacturer's instructions. Two hundred and fifty nanograms of RNA were used for gene expression analysis performed by means of the Human PanCancer Immune Panel (NanoString, Seattle, Washington, USA). The NanoStringNorm package for $\mathrm{R}$ software was used to assess the quality and process data; the geometric mean of the counts relative to each sample, the mean plus two SDs and the total sum of counts options were used to correct the data for technical, background and batch effect issues, respectively. The total expression counts of the housekeeping genes were used to account for inter sample variations and normalize the data. Canberra distance and Ward's linkage criteria were used as distance metric and linkage methods to assess for natural grouping of samples. The Voom/limma method was used for differential expression analysis of raw counts under standard parameters. Y-related genes were removed from the analysis to prevent biased detections, given the high prevalence of females among patients with responding tumors in the subgroup of patients with available FFPE tissue.

\section{Fluorescence-activated cell sorting (FACS) analysis of peripheral blood monocytic cells}

Peripheral blood mononuclear cells (PBMCs) were obtained from patients by Ficoll density gradient centrifugation (Ficoll-Paque PLUS, GE Healthcare). Multicolor staining for monocytes was performed on cryopreserved samples. Cells were thawed in RPMI medium supplemented with $10 \%$ human serum; $2 \times 10^{6}$ PBMCs were resuspended in $100 \mu \mathrm{L}$ of staining buffer (phosphatebuffered saline $[\mathrm{PBS}]+2 \%$ fetal bovine serum $[\mathrm{FBS}]$ ) and incubated with FcR Blocking Reagent (Miltenyi Biotec), with antibodies against the indicated cell surface markers and Zombie Aqua (Fixable viability dye, Biolegend, Cat\#423102) in staining buffer for $30 \mathrm{~min}$ at $4^{\circ} \mathrm{C}$. The following human antibodies were used: CD3-PcP-Cy5.5 (BD, Cat\#560835), CD14-APC (BD, Cat\#345787), CD16PE-Cy7 (BD, Cat\#557744), CD19-PcP-Cy5.5 (Biolegend, Cat\#302230), CD45-BV421 (BD, Cat\#563879), CD56PcP-Cy5.5 (Biolegend, Cat\#362506) and HLA-DR-FITC (BD, Cat\#555811). Cells were acquired by 13-color Cytoflex S cytometer (Beckman Coulter). Instrument optical alignment and fluidics were routinely checked by CytoFLEX Daily QC Fluorospheres (Beckman Coulter, Cat\#B53230). Data were analyzed with FlowJo software (V.10.7.1 FlowJo, LLC), after excluding doublets (on side scatter area [SSC-A] vs side scatter height [SSC-H] dot plots) and by gating on live (Zombie Aqua negative) cells. The t-test was used to compare frequencies between groups. 
Table 1 Individual patients' characteristics and clinical outcomes

\begin{tabular}{|c|c|c|c|c|c|c|c|c|c|}
\hline UPN & Age & Sex & $\begin{array}{l}\text { NHL type } \\
\text { (stage) }\end{array}$ & $\begin{array}{l}\text { Disease } \\
\text { burden* }\end{array}$ & $\begin{array}{l}\text { Previous treatment } \\
\text { (response/duration) }\end{array}$ & Best response & PD & PFS & os \\
\hline \multicolumn{10}{|c|}{ Patients with responding disease } \\
\hline 12 & 65 & $\mathrm{M}$ & LP (IA) & Low & 6 CVP (CR/36 mo) & CR & No & $177+$ & $177+$ \\
\hline 13 & 72 & $\mathrm{~F}$ & $\begin{array}{l}\text { FL grade } 1 \\
\text { (IIA) }\end{array}$ & Low & $\begin{array}{l}6 \text { CVP (PR/16 mo); } \\
4 \text { rituximab (CR/24 mo) }\end{array}$ & CR & No & $183+$ & $183+$ \\
\hline 14 & 52 & $\mathrm{~F}$ & $\begin{array}{l}\text { FL grade } 3 A \\
\text { (IVA) }\end{array}$ & Low & $\begin{array}{l}6 \text { R-MegaCEOP (PR/10 mo); } \\
\text { HDS (CR/6 mo) }\end{array}$ & CR & No & $177+$ & $177+$ \\
\hline 4 & 51 & M & $\begin{array}{l}\text { FL grade } 2 \\
\text { (IA) }\end{array}$ & Low & $\begin{array}{l}4 \text { rituximab (CR/24 mo); } \\
\text { RT } 30 \text { Gy (CR/24 mo) }\end{array}$ & $\mathrm{CR}$ & Yes & 154 & $199+$ \\
\hline 1 & 49 & $\mathrm{~F}$ & LP (IVA) & Low & $\begin{array}{l}6 \text { CVP (CR/48 mo); } \\
8 \text { rituximab (PR/72 mo) }\end{array}$ & PR & Yes & 63 & $202+$ \\
\hline
\end{tabular}

\section{Patients with stable disease}

\begin{tabular}{|c|c|c|c|c|c|c|c|c|c|}
\hline 2 & 60 & M & LP (IVA) & Low & $\begin{array}{l}6 \mathrm{CVP}(\mathrm{PR} / 36 \mathrm{mo}) ; \\
6 \text { rituximab }(\mathrm{CR} / 48 \mathrm{mo})\end{array}$ & SD & Yes & 59 & 169 \\
\hline 9 & 63 & M & LP (IVA) & High & $\begin{array}{l}8 \text { rituximab (PR/16 mo); } \\
4 \text { CVP (PR/18 mo); } \\
4 \text { R-CHOP (SD/32 mo) }\end{array}$ & SD & Yes & 70 & $186+$ \\
\hline 10 & 54 & M & $\begin{array}{l}\text { FL grade } 1 \\
\text { (IVA) }\end{array}$ & High & 8 R-CVP (CR/36 mo) & SD & Yes & 70 & $187+$ \\
\hline 11 & 72 & M & $\begin{array}{l}\text { FL grade } 2 \\
\text { (IVB) }\end{array}$ & High & 18 mo leukeran (CR/84 mo) & SD & Yes & 74 & $184+$ \\
\hline 16 & 55 & $\mathrm{~F}$ & $\begin{array}{l}\text { FL grade } 1 \\
\text { (IVA) }\end{array}$ & Low & $6 \mathrm{CVP}(\mathrm{CR} / 24 \mathrm{mo})$ & SD & Yes & 159 & $174+$ \\
\hline 17 & 65 & M & LP (IIIA) & Low & $8 \mathrm{CVP}(\mathrm{CR} / 98 \mathrm{mo})$ & SD & Yes & 11 & $174+$ \\
\hline \multicolumn{10}{|c|}{ Patients with progressive disease } \\
\hline 3 & 60 & M & $\begin{array}{l}\text { FL grade } 2 \\
\text { (IVA) }\end{array}$ & Low & $\begin{array}{l}8 \mathrm{CHOP}(\mathrm{PR} / 16 \mathrm{mo}) ; \\
6 \text { rituximab (PR/8 mo) }\end{array}$ & PD & Yes & 1 & $199+$ \\
\hline 15 & 72 & M & $\operatorname{LP}(\mathrm{IA})$ & High & $\begin{array}{l}3 \mathrm{CHOP}(\mathrm{PR} / 8 \mathrm{mo}) ; \\
\text { splenectomy +RT (PR/12 } \\
\text { mo); } \\
12 \text { mo leukeran (PR/7 mo); } \\
\text { HDS (CR/12 mo); } \\
4 \text { rituximab (PD/na) }\end{array}$ & PD & Yes & 1 & 21 \\
\hline
\end{tabular}

*Low disease burden was defined as the presence of nodal masses $\leq 3 \mathrm{~cm}$ and no massive bone marrow involvement, whereas high disease burden was defined as the presence of nodal masses $>3 \mathrm{~cm}$ and/or massive bone marrow involvement.

+ , specific event not experienced at the data cut-off date; CEOP, cyclophosphamide, epi-adryamicin, vincristine, and prednisone; $\mathrm{CHOP}$, cyclophosphamide, adryamicin, vincristine and prednisone; CHOP-bleo, CHOP plus bleomycin; CR, complete response; CVP, cyclophosphamide, vincristine and prednisone; F, female; FL, follicular lymphoma; HDS, high-dose sequential chemotherapy; LP, lymphoplasmocytoid NHL; M, male; mo, months; NHL, non-Hodgkin lymphoma; PD, progressive disease; PR, partial response; R-Benda, rituximab and bendamustine; R-CEOP, rituximab plus CEOP; R-CVP, rituximab plus CVP; RT, radiotherapy; SD, stable disease; UPN, unique progressive number.

\section{RESULTS}

A total of 18 patients were enrolled between January 2003 and May 2005: 12 patients (67\%) with FL and 6 patients $(33 \%)$ with LP. Individual patients' characteristics and clinical outcomes are reported in table 1. All patients received the planned four doses of vaccine. After 
a median follow-up of 15.4 years (IQR 14.8-16.1), we observed 14 events for PFS and four events for OS. Five patients (28\%) experienced a complete response (CR), three patients $(17 \%)$ a partial response (PR), six patients $(33 \%)$ a stabilization of disease (SD) and four patients $(22 \%)$ a progression of disease as best response, for an objective response rate $(\mathrm{CR}+\mathrm{PR})$ of $45 \%$ and a clinical benefit rate $(\mathrm{CR}+\mathrm{PR}+\mathrm{SD})$ of $78 \%$.

Interestingly, two patients who experienced a stabilization of disease as best response at the time of the previous report eventually achieved a complete response (UPN 4 and 18) (figure 1A). A decrease was observed in the sum of the product of the diameters of the largest dominant nodes between $30 \%$ and $45 \%$ (SD per Cheson criteria) at the first tumor evaluation by means of CT scan and then the residual disease remained stable. For both patients (UPN 4 and 18), a complete disappearance of the detectable residual disease was observed after 74 months and 53 months, respectively, from the last vaccine dose administration. Of note, only dimensional criteria by means of CT scan were used in these patients for response evaluation since no pretreatment functional imaging (ie, positron emission tomography) was available. Four patients (22\%) were in ongoing CR at the data cut-off date of the present report (figure 1A). In patients with responding disease, median time-to-response was 2 months (range 1-74 months) and median duration of response was 80 months (95\% CI 52 to NA).

A trend (even if not significant, most likely due to the small sample size) was observed for a higher response rate in patients with low disease burden (ie, nodal masses $\leq 3 \mathrm{~cm}$ and no massive bone marrow involvement, $7 / 11$ patients, 64\%) in comparison with patients with high disease burden (ie, nodal masses $>3 \mathrm{~cm}$ and/or massive bone marrow involvement, $1 / 7$ patients, 14\%; Fisher's exact test $\mathrm{p}=0.066)$ and in female patients $(4 / 5,80 \%)$ compared with male patients $(4 / 13,30.8 \%$; Fisher's exact test $\mathrm{p}=0.118)$. No differences were observed in terms of response rate according to NHL type. The 5-year and 10-year PFS rates were $55.6 \%$ (95\% CI 36.8 to 84 ) and $33.3 \%$ (95\% CI 17.3 to 64.1 ), respectively, whereas the 10-year OS rate was $83.3 \%$ (95\% CI 67.8 to 100) (figure 1B). No differences were observed in terms of PFS and OS according to disease burden or NHL type. Interestingly, female patients experienced a better PFS (logrank $\mathrm{p}=0.016)$ and a trend toward a better OS (log-rank $\mathrm{p}=0.186$ ) compared with male patients (online supplemental figure 1). No late toxicities or signs of vaccinerelated, delayed autoimmunity were reported during the extended follow-up period.

To expand the biomarker analysis previously performed, we carried out an immune-targeted gene expression profiling in a subgroup of 11 patients with available FFPE tumor tissue from a pre-treatment biopsy. We found 10 differentially expressed genes in responder versus nonresponder tumors: KIT, ATG12, TNFRSF10C, PBK, ITGA2, GATA3, CLU, NCAM1, SYT17 and LTK (figure 2A). Furthermore, since the role of the myeloid compartment was not investigated in our previous works, we also characterized the baseline phenotype of peripheral monocytic cells taking advantage of the availability of frozen pretreatment PBMCs in a subgroup of 14 patients. The gating strategy is illustrated in online supplemental figure 2. We observed a higher percentage of $\mathrm{CD} 14^{++} \mathrm{CD} 16^{+}$cells (intermediate monocytes) in patients with responding tumors, whereas no difference in terms of classical and non-classical monocyte subsets was observed (figure 2B).

\section{DISCUSSION}

The present 15-year follow-up analysis of our pilot study confirmed the benefit of active immunization with DCs loaded with autologous, heat-shocked and UV-C treated tumor cells in relapsed iNHL. Of note, this is the first analysis, to our knowledge, reporting on the long-term follow-up of patients with relapse iNHL treated with a cellular vaccine, and we observed that a non-negligible fraction of patients (22\%) experienced a long-lasting complete response. The response rate reported in our pilot study was consistent with those of other studies investigating cellular DC-based vaccination in relapsed iNHL and ranging from $40 \%$ to $50 \%$. $^{13-15}$ On the contrary, the observed clinical benefit of idiotype vaccination (a different vaccination strategy investigated in two randomized clinical trials as a consolidation therapy after the first remission) was scant, probably because idiotype vaccination may elicit only a $B$ cell response against a single tumor antigen. ${ }^{16}{ }^{17}$ Indeed, the differentially expressed genes in responder versus non-responder tumors exploratively identified in the present study suggest a possible contribution of autophagy (ATG12), innate immunity (CLU) and cell adhesion (ITGA2 and NCAMI) in determining the antitumor activity of our DC-based vaccination strategy (in addition to the previously demonstrated role for $\mathrm{B}, \mathrm{T}$ and NK cell response). The exploratory characterization of circulating monocytic cells also suggested a possible contribution of intermediate monocytes to the antitumor activity observed in our study. Notably, intermediate monocytes are a particular subset of monocytic cells that are predisposed for antigen presentation, ${ }^{18}$ are involved in the phagocytosis of antibodyopsonized cells ${ }^{19}$ and ultimately warrant further investigation. Lastly, also the sex-associated difference in survival outcomes that we observed (in favor of female patients) needs to be validated in larger cohorts of cancer patients treated with similar vaccination strategies, particularly because the influence of sex in patients treated with our DC-based vaccine had an opposite impact in comparison with what reported for patients treated with immune-checkpoint inhibitors. ${ }^{20}$

Given the long-term disease control observed, we believe that our vaccination strategy still warrants investigation with the aim of extending the proportion of patients who can achieve such durable clinical benefit. Since we previously demonstrated that immunogenic cell death potentiates the antitumor activity of DC-based vaccination, ${ }^{10}$ combinatorial approaches with other local or systemic immunomodulatory strategies might extend the effectiveness of our cellular vaccine. In this regard, a promising clinical activity was 
A

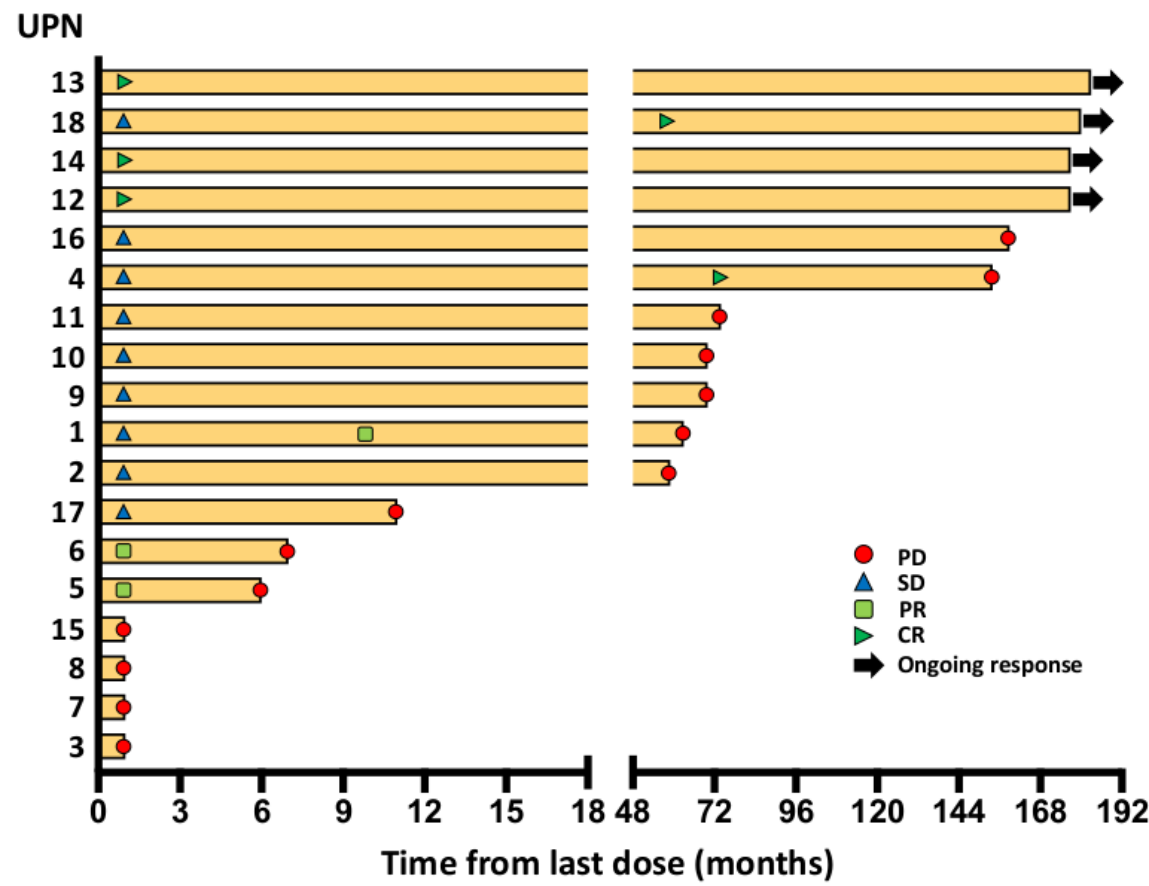

B

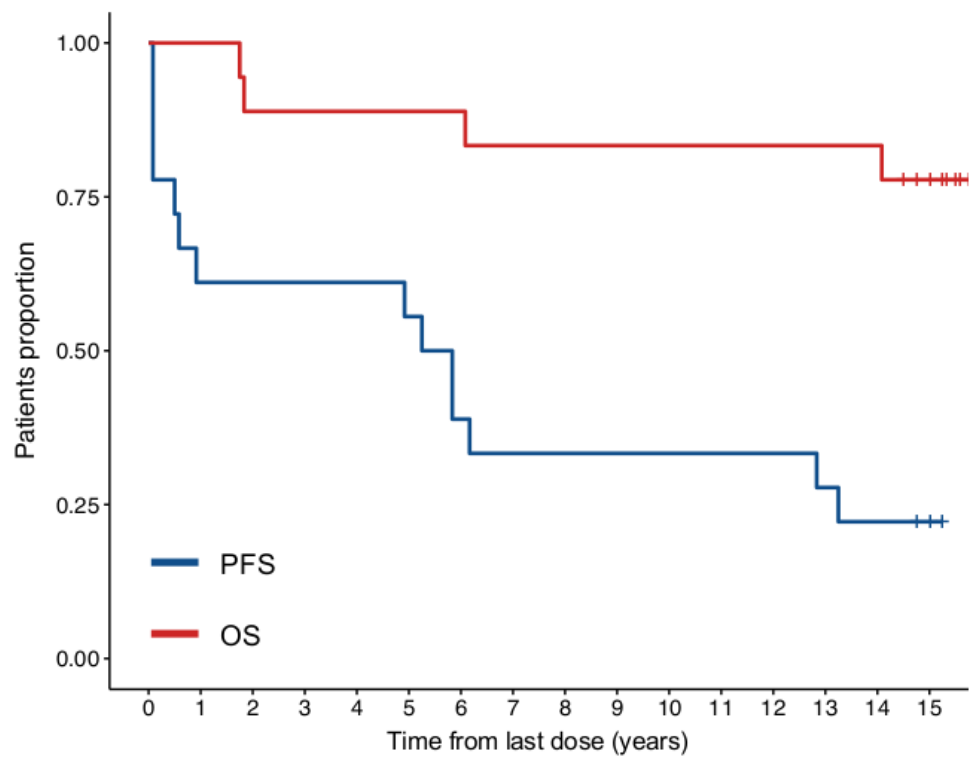

Number at risk

\begin{tabular}{|c|c|c|c|c|c|c|c|c|c|c|c|c|c|c|c|}
\hline 18 & 11 & 11 & 11 & 11 & 10 & 7 & 6 & 6 & 6 & 6 & 6 & 6 & 5 & 4 & 2 \\
\hline 18 & 18 & 16 & 16 & 16 & 16 & 16 & 15 & 15 & 15 & 15 & 15 & 15 & 15 & 15 & 10 \\
\hline 0 & 1 & 2 & 3 & 4 & 5 & 6 & 7 & 8 & 9 & 10 & 11 & 12 & 13 & 14 & 15 \\
\hline
\end{tabular}

Figure 1 Long-term clinical outcomes of patients with relapsed indolent non-Hodgkin lymphoma vaccinated with tumorloaded dendritic cells. Panel A shows the swimmer plot illustrating the pattern and the duration of response. The red square indicates a PD, the blue triangle indicates an SD, the light green square indicates a PR, the dark green triangle indicates a CR and the black arrow indicates an ongoing response at the time of data cut-off date. Panel B shows the Kaplan-Meier estimates for progression-free survival (PFS) and overall survival (OS). Blue line indicates PFS, whereas red line indicates OS. The 5-year and 10 -year PFS rates were $55.6 \%(95 \% \mathrm{Cl} 36.8$ to 84$)$ and $33.3 \%$ (95\% Cl 17.3 to 64.1$)$, respectively, whereas the 10 -year OS rate was $83.3 \%$ (95\% Cl 67.8 to 100). CR, complete response; PD, progressive disease; PR, partial response; SD, stable disease; UPN, unique progressive number. 
A

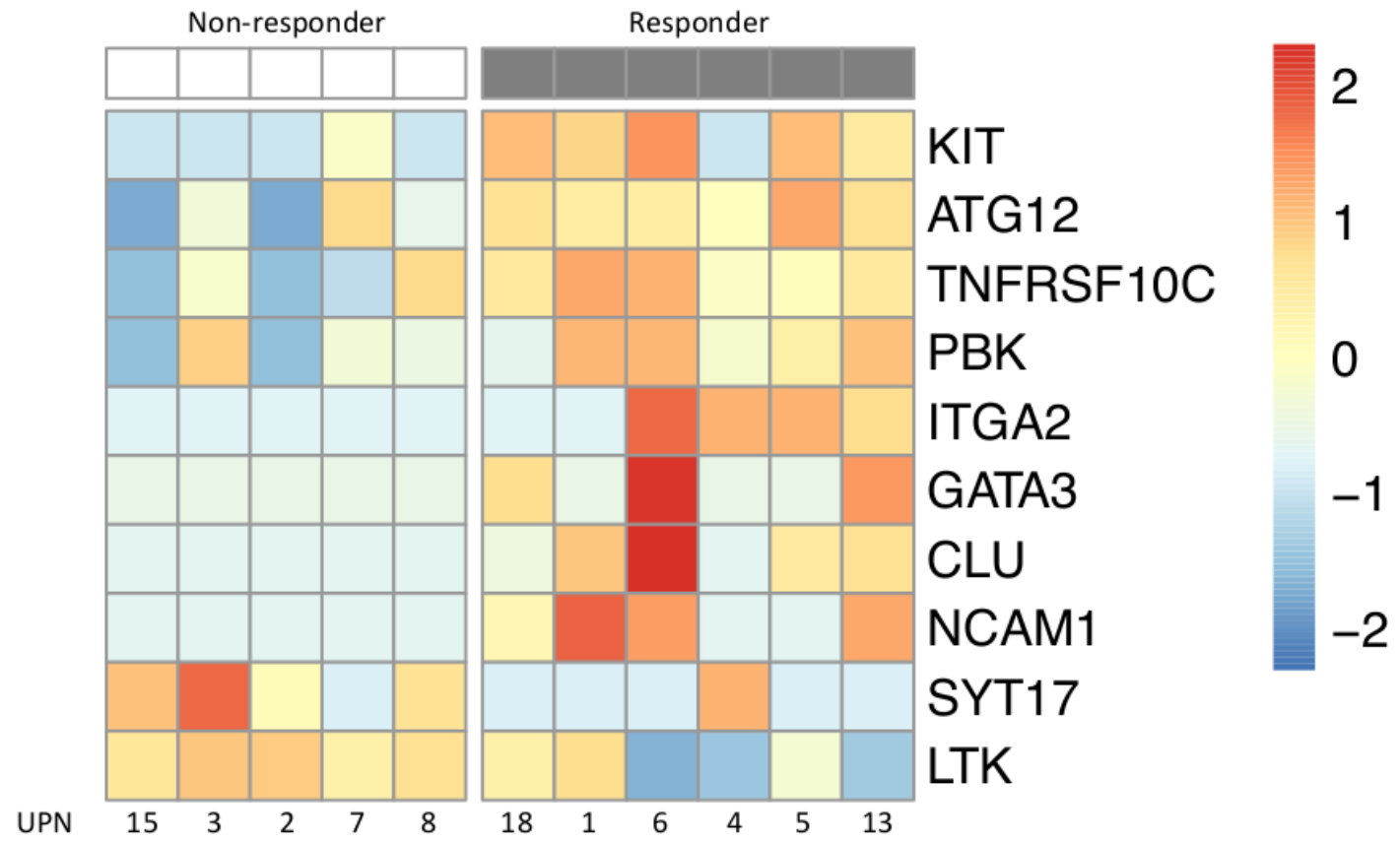

B

Gated on $\mathrm{CD}^{+} 5^{+} \mathrm{CD} 14^{+}$

\section{$\%$ of CD14 ${ }^{++} \mathrm{CD} 16^{-}$ (Classical monocytes)}

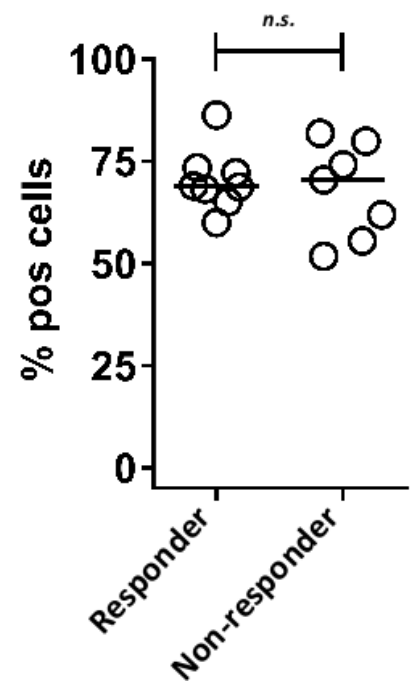

$\%$ of $\mathrm{CD}^{++}{ }^{++} \mathrm{CD} 16^{+}$ (Intermediate monocytes)

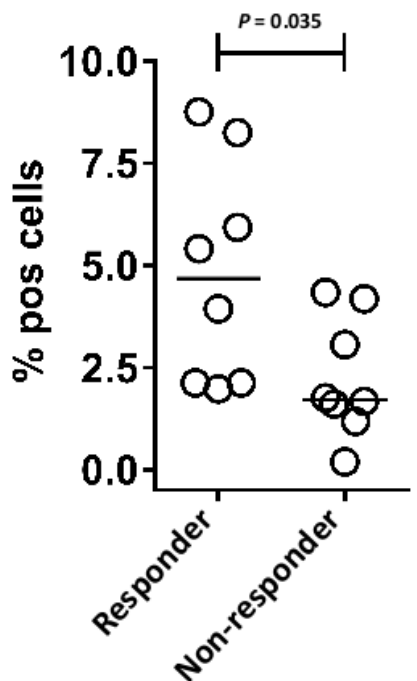

$\%$ of CD14 ${ }^{+}$CD $16^{++}$

(Non-classical monocytes)

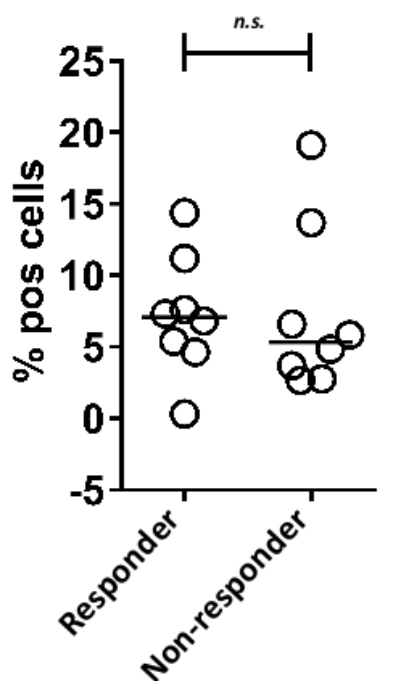

Figure 2 Expanded biomarker analysis in patients with relapsed indolent non-Hodgkin lymphoma vaccinated with tumorloaded dendritic cells. Panel A shows the heatmap of the 10 differentially expressed genes between responder and nonresponder tumors ( $p$ value $<0.05$ ) in a subgroup of 11 patients with available FFPE pretreatment tissue. The color scale represents the relative gene expression changes normalized by the SD. Panel B shows the frequency of peripheral monocytic cell subsets at baseline in patients with responder compared with non-responder tumors in a subgroup of 14 patients with available frozen PBMCs. FFPE, formalin-fixed and paraffin-embedded; PBMCs, peripheral mononuclear cells. 
observed in iNHL patients vaccinated in situ with a Toll-like receptor (TLR) 9 agonist in combination with low-dose radiotherapy. ${ }^{21}$ Further research efforts are also needed to explore the efficacy of active DC-based vaccination in earlier lines of therapy, especially in combination with anti-CD20 agents, since preclinical in vivo evidence showed a synergism between anti-CD20 antibodies and DC vaccines in iNHL, ${ }^{22}$ and the combination of autologous DCs, local radiotherapy and lowdose rituximab was able to induced clinical responses with an overall response rate of $36 \%$ in advanced FL patients (the majority of whom had not received any previous therapy). ${ }^{23}$ Nonetheless, a possible synergy between the vaccination with autologous tumor-loaded DCs and immune-checkpoint inhibitors should be explored. Even if the clinical efficacy of PD-1/PD-L1 blockade in iNHL has been disappointing compared with Hodgkin lymphoma, ${ }^{24}$ emerging evidence indicates that the effectiveness of PD-1 blockade in this setting strongly relies on the cross-presentation of tumor antigens by DCs, and PD-1 blockade was able to potentiate the antitumor activity of in situ vaccination in a murine model of iNHL. ${ }^{25}$ Accordingly, in patients with iNHL vaccinated in situ with a combination of a FLT3 ligand, radiotherapy and a TLR3 agonist, the dynamic of PD-1-driven $T$ cell exhaustion was correlated with overall response, suggesting a possible clinical benefit from the addition of PD-1 blockade to DC-based vaccines. ${ }^{25}$

\section{Author affiliations}

${ }^{1}$ Immunotherapy and Innovative Therapeutics Unit, Medical Oncology and Hematology Department, Fondazione IRCCS Istituto Nazionale dei Tumori, Milan, Italy

${ }^{2}$ Department of Pathology and Laboratory Medicine, Fondazione IRCCS Istituto Nazionale dei Tumori, Milan, Italy

${ }^{3}$ Human Tumors Immunobiology Unit, Department of Research, Fondazione IRCCS Istituto Nazionale dei Tumori, Milan, Italy

${ }^{4}$ Molecular Targeting Unit, Department of Research, Fondazione IRCCS Istituto Nazionale dei Tumori, Milan, Italy

${ }^{5}$ Hematology Division, Medical Oncology and Hematology Department, Fondazione IRCCS Istituto Nazionale dei Tumori, Milan, Italy

${ }^{6}$ Swim Across America and Ludwig Collaborative Laboratory, Immunology Program, Parker Institute for Cancer Immunotherapy, Memorial Sloan Kettering Cancer Center, New York, NY, USA

${ }^{7}$ Oncology and Hemato-oncology Department, University of Milan, Milan, Italy ${ }^{8}$ European Institute of Oncology, Milan, Italy

Contributors MDN, AA and AMG designed the original study; RM, SMP, MM, LD, $\mathrm{PM}, \mathrm{AC}$ and $\mathrm{RZ}$ performed the clinical and translational research related to the original study; GF, MA, LD, PM and FDS collected data for the long-term follow-up study; LA and SB performed the targeted gene expression profiling; FS performed flow cytometry analysis of peripheral blood samples; GF performed statistical analysis; GF, MA, LA, SB, FDB and MDN analyzed and interpreted data; GF and MA wrote the manuscript; LA, SB, FS, RM, SMP, AA, FdB and MDN reviewed the manuscript.

Funding This work has been supported by the MICROTHER grant to MDN funded under the program ERA-NET TRANSCAN-2 JTC 2015 by the Italian National Institute of Health (Istituto Superiore di Sanità).

Competing interests None declared.

Patient consent for publication Not required.

Ethics approval The study protocol was approved by the Institutional Review Board and Ethical Committee of the Fondazione IRCCS Istituto Nazionale dei Tumori of Milan. All patients gave written informed consent.

Provenance and peer review Not commissioned; externally peer reviewed.
Data availability statement Data are available on reasonable request. The datasets generated during and/or analyzed during the current study are available from the corresponding author on reasonable request.

Supplemental material This content has been supplied by the author(s). It has not been vetted by BMJ Publishing Group Limited (BMJ) and may not have been peer-reviewed. Any opinions or recommendations discussed are solely those of the author(s) and are not endorsed by BMJ. BMJ disclaims all liability and responsibility arising from any reliance placed on the content. Where the content includes any translated material, BMJ does not warrant the accuracy and reliability of the translations (including but not limited to local regulations, clinical guidelines, terminology, drug names and drug dosages), and is not responsible for any error and/or omissions arising from translation and adaptation or otherwise.

Open access This is an open access article distributed in accordance with the Creative Commons Attribution Non Commercial (CC BY-NC 4.0) license, which permits others to distribute, remix, adapt, build upon this work non-commercially, and license their derivative works on different terms, provided the original work is properly cited, appropriate credit is given, any changes made indicated, and the use is non-commercial. See http://creativecommons.org/licenses/by-nc/4.0/.

\section{ORCID iD}

Giovanni Fucà http://orcid.org/0000-0002-1560-2253

\section{REFERENCES}

1 Sapkota S, Shaikh H. Non-Hodgkin lymphoma . Treasure Island (FL: StatPearls Publishing, 2020. https://www.ncbi.nlm.nih.gov/books/ NBK559328/. (cited 2020 Oct 28).

2 Leonard JP, Trneny M, Izutsu K, et al. Augment: a phase III study of lenalidomide plus rituximab versus placebo plus rituximab in relapsed or refractory indolent lymphoma. J Clin Oncol 2019;37:1188-99.

3 Dreyling M, Santoro A, Mollica L, et al. Phosphatidylinositol 3-kinase inhibition by Copanlisib in relapsed or refractory indolent lymphoma. $J$ Clin Oncol 2017;35:3898-905.

4 Sehn LH, Chua N, Mayer J, et al. Obinutuzumab plus bendamustine versus bendamustine monotherapy in patients with rituximabrefractory indolent non-Hodgkin lymphoma (GADOLIN): a randomised, controlled, open-label, multicentre, phase 3 trial. Lancet Oncol 2016;17:1081-93.

5 Gopal AK, Kahl BS, de Vos S, et al. Pi3K $\delta$ inhibition by idelalisib in patients with relapsed indolent lymphoma. N Engl J Med 2014;370:1008-18.

6 Wang ML, Rule S, Martin P, et al. Targeting Btk with ibrutinib in relapsed or refractory mantle-cell lymphoma. $N$ Engl J Med 2013;369:507-16.

7 Treon SP, Tripsas CK, Meid K, et al. Ibrutinib in previously treated Waldenström's macroglobulinemia. N Engl J Med 2015;372:1430-40.

8 Di Nicola M, Zappasodi R, Carlo-Stella C, et al. Vaccination with autologous tumor-loaded dendritic cells induces clinical and immunologic responses in indolent B-cell lymphoma patients with relapsed and measurable disease: a pilot study. Blood 2009;113:18-27.

9 Zappasodi R, Bongarzone I, Ghedini GC, et al. Serological identification of HSP105 as a novel non-Hodgkin lymphoma therapeutic target. Blood 2011;118:4421-30.

10 Zappasodi R, Pupa SM, Ghedini GC, et al. Improved clinical outcome in indolent B-cell lymphoma patients vaccinated with autologous tumor cells experiencing immunogenic death. Cancer Res 2010;70:9062-72.

11 Harris NL, Jaffe ES, Stein H, et al. A revised European-American classification of lymphoid neoplasms: a proposal from the International lymphoma Study Group. Blood 1994;84:1361-92.

12 Cheson BD, Pfistner B, Juweid ME, et al. Revised response criteria for malignant lymphoma. J Clin Oncol 2007;25:579-86.

13 Lin Y, Atwell T, Weisbrod A, et al. Dendritic cell vaccine treatment for B-cell non-Hodgkin lymphoma: clinical trial in progress. Blood 2014; $124: 4474$

14 Timmerman JM, Czerwinski DK, Davis TA, et al. Idiotype-pulsed dendritic cell vaccination for B-cell lymphoma: clinical and immune responses in 35 patients. Blood 2002;99:1517-26.

15 Hsu FJ, Benike C, Fagnoni F, et al. Vaccination of patients with B-cell lymphoma using autologous antigen-pulsed dendritic cells. Nat Med 1996;2:52-8. 
16 Schuster SJ, Neelapu SS, Gause BL, et al. Vaccination with patientspecific tumor-derived antigen in first remission improves diseasefree survival in follicular lymphoma. J Clin Oncol 2011;29:2787-94.

17 Levy R, Ganjoo KN, Leonard JP, et al. Active idiotypic vaccination versus control immunotherapy for follicular lymphoma. J Clin Oncol 2014;32:1797-803.

18 Zawada AM, Rogacev KS, Rotter B, et al. SuperSAGE evidence for CD14++CD16+ monocytes as a third monocyte subset. Blood 2011;118:e50-61.

19 Zhou J, Feng G, Beeson J, et al. CD14(hi)CD16+ monocytes phagocytose antibody-opsonised Plasmodium falciparum infected erythrocytes more efficiently than other monocyte subsets, and require CD16 and complement to do so. BMC Med 2015;13:154

20 Conforti F, Pala L, Bagnardi V, et al. Cancer immunotherapy efficacy and patients' sex: a systematic review and meta-analysis. Lancet Oncol 2018;19:737-46.
21 Brody JD, Ai WZ, Czerwinski DK, et al. In situ vaccination with a TLR9 agonist induces systemic lymphoma regression: a phase I/II study. J Clin Oncol 2010;28:4324-32.

22 Manzur S, Cohen S, Haimovich J, et al. Enhanced therapeutic effect of B cell-depleting anti-CD20 antibodies upon combination with in-situ dendritic cell vaccination in advanced lymphoma. Clin Exp Immunol 2012;170:291-9.

23 Kolstad A, Kumari S, Walczak M, et al. Sequential intranodal immunotherapy induces antitumor immunity and correlated regression of disseminated follicular lymphoma. Blood 2015;125:82-9.

24 Ansell SM, Lin Y. Immunotherapy of lymphomas. J Clin Invest 2020;130:1576-85

25 Hammerich L, Marron TU, Upadhyay R, et al. Systemic clinical tumor regressions and potentiation of PD1 blockade with in situ vaccination. Nat Med 2019;25:814-24. 